\title{
Implementation of an Awareness Program and Lifestyle Intervention on Polycystic Ovarian Syndrome among Adolescent Schoolgirls in India
}

\section{Valarmathi Selvaraj $^{1 *}$, Jain Vanitha ${ }^{2}$, Fabiola M Dhanraj ${ }^{3}$, Prema Sekar ${ }^{4}$ and Anitha Rajendra Babu ${ }^{5}$}

${ }^{1} \mathrm{PhD}(\mathrm{N})$ Scholar, Meenakshi Academy of Higher Education and Research, Virugambakkam, Chennai, India

${ }^{2}$ Professor, Director of Nursing Shenbaga College of Nursing, Chennai, India

${ }^{3}$ Principal, Arulmigu Meenakshi College of Nursing, Kancheepuram, India

${ }^{4}$ Principal, Annai Veilankanni College of Nursing, Perungalatur, India

${ }^{5}$ Principal, Rajalakshmi College of Nursing, Chennai, India

*Corresponding Author: Valarmathi Selvaraj, PhD (N) Scholar, Meenakshi Academy of Higher Education and Research, Virugambakkam, Chennai, India.
Received: March 06, 2020

Published: April 29, 2020

(C) All rights are reserved by Valarmathi

Selvaraj., et al.

\section{Abstract}

Authors share their experiences from a research on polycystic ovarian syndrome (PCOS) risk among adolescent schoolgirls in a South Indian state. One hundred and twenty school going adolescent girls from a government funded school in Southern India were assessed for PCOS risk, among which 40 had PCOS risk (moderate risk 36, high risk 4). These 40 were grouped in to either experimental or control which 20 each. Experimental group received awareness program and lifestyle modifications (yoga and exercise) by the researcher in coordination with the schoolteachers at the school premises. Pretest knowledge assessment showed, $16(80 \%)$ in the experimental and $15(75 \%)$ on the control group had 'moderate' knowledge. Post intervention, 15 (75\%) had adequate knowledge in the experimental group and $9(45 \%)$ in the control group. Knowledge score during pretest was mean 11.30 ; SD 4.91, $t=5.27 ; p=0.000$ in the experimental group, and 11.25; $S D=4.44, t=2.85 ; p=00.01$ in the control group. Knowledge score of post-test was 11.30; SD 4.91; $\mathrm{t}=5.27 ; \mathrm{p}=0.000$ in the experimental and the mean 14.35; S.D 4.44; $\mathrm{t}=2.85 ; \mathrm{p}=0.01$ in the control group. Attitude score during pretest was 51.80; $\mathrm{SD}=11.12, \mathrm{t}=0.01 ; \mathrm{p}=0.000$ in the experimental and $53.45 \mathrm{SD}=5.91 ; \mathrm{t}=2.99 ; \mathrm{p}=$ 00.01 ) in the control group. Attitude score during posttest was mean 53.45; $\mathrm{SD}=5.91, \mathrm{t}=2.99 ; \mathrm{p}=0.1$ in the experimental group and $53.45 \mathrm{SD}=5.91 ; \mathrm{t}=2.99 ; \mathrm{p}=00.01$ in the control group. Improvements in knowledge and attitude score demonstrates the feasibility of lifestyle intervention targeted at adolescent girls, with PCOS risk, in school premises.

Keywords: Adolescent Girls; Attitude; Knowledge; Polycystic Ovarian Syndrome; Risk Assessment

\section{Introduction}

PCOS is a hormonal disorder known to affect the females during their reproductive age (12 - 45 years). In India, it is considered as a growing problem with prevalence rate of among South Indian adolescent girls to be $9.13 \%$ [1]. PCOS is considered as metabolic and reproductive disorder characterized by excessive ovarian androgen production and chronic anovulation, which are responsible for irregular menstrual bleeding and hyperandrogens state (excessive male hormone) in adolescent girls [2]. As per the Rotterdam and Androgen Excess-PCOS Society criteria, there are three clinical phenotypes of PCOs (Frank PCOS, Ovulatory PCOS and Non-PCO PCOS (oligomenorrhea, hyperandrogenism, and normal ovaries). In addition, the Rotterdam criteria also recognize another type 'Normoandrogenic PCOS' [3]. In a study conducted among 100 women aged 15 - 25 years attending outpatient department in South India, 50 women had the history of irregular menstrual history and re- maining 50 had regular menstrual history [4]. PCOS usually starts in adolescent stage and affect during childbearing age [5]. During adolescent stage, most of the cases are likely to be underdiagnosed [6]. It is diagnosed by the presence of 12 or more follicles in each ovary, increased ovarian volume $\left(10 \mathrm{~cm}^{3}\right)$ and measuring $2-9 \mathrm{~mm}$ in diameter [7]. Studies have investigated the effect of exercise on psychological outcomes in PCOS. A small, non-randomized study finding showed that overweight and obese women with PCOS reported that a six-month, self-directed brisk walking program improved body image distress. Yogic lifestyle modifications, a form of holistic mind-body medicine is a simple and easy to practice lifestyle process which is known to reduce anxiety symptoms related to PCOS [8-10].

There is an increasing number of adolescents presenting with signs of PCOS suggesting a higher possibility for cardiovascular, metabolic and depressive disorders [11-13]. Lifestyle modifica- 
tion such as yoga, exercise and diet help to reduce the risk of getting PCOS. Yogasana, commonly mentioned as 'Yoga' is a form of medicine developed thousands of years ago and has been popular in India for generations. It is simple and can be practiced by everyone and does not need much of infrastructure. Hence yoga is considered as a simple and easy means of exercise. Yoga helps to trigger the function of all endocrine glands and nerve plexus and help to maintain the hormonal level and to improve the fertility $[14,15]$. Risk assessment and lifestyle modifications appear to be the most useful strategy in approaching individuals at high risk for PCOS. India witnessed about 36\% increase in PCOS cases in the last decade [8]. It is established that a small change in lifestyle are known decrease the symptom of PCOS. PCOS is a common problem among adolescent girls in India and early risk assessment and lifestyle interventions can be valuable alternative to treatment of the full-blown condition.

\section{Aim of the Study}

The aim of our study was to identify the PCOS risk among adolescent schoolgirls, to evaluate their knowledge and attitude towards PCOS, and to evaluate the effectiveness of awareness program aimed at improving knowledge, awareness and minimizing PCOS risks.

\section{Methods}

Study design

This research followed a quasi-experimental design in which the control group did not receive any intervention and experimental received intervention provided by the researcher.

\section{Study population}

In this present study, the population is school going adolescence girls who were studying in grades $10-12$ at Government Girls Higher Secondary School, Kamaraj Nagar, Avadi, Chennai, South India. At the time of the research, the school had a total of 948 females.

\section{Ethical approval}

The Ethical approval for the research was obtained from the Billroth Hospital Ethical Committee, Chennai, Tamilnadu State, India.

\section{Sample selection}

Since PCOS is common among adolescent girls and most of the adolescent girls attained their menarche before they studying $10^{\text {th }}$ grades.

\section{Inclusion criteria}

Participants who were adolescent girls who were studying in $10^{\text {th }}$ to $12^{\text {th }}$ grades, attained menarche for past 6 months during data collection, present at the time of data collection, who can read, speak and understand the local language (Tamil).

\section{Exclusion criteria}

Adolescent girls who were not willing to participate in this research and perform lifestyle modifications, not attained menarche since attained menarche is the important in assessing the risk assessment, undergone educational program on PCOS through school education or in the community. Students who were routinely doing acrobatic exercise doing morning or evening, regularly doing Yoga in the morning or evening, sick on the time of data collection due to severe pain during menses, fever etc, and diagnosed as PCOS and taking medicine regularly, were also excluded.

\section{Study tools}

\section{Knowledge questionnaire}

This questionnaire was developed by the researcher. It has 25 multiple choice questions covering the anatomy of the reproductive system, definition, causes, signs and symptoms, diagnostic evaluation, complication and prevention of PCOS. A score of ' 1 ' and ' 0 ' was given to the correct and wrong answers respectively. The Cronbach ' $\alpha$ ' value of knowledge tools was 0.84 .

\section{Attitude questionnaire}

This questionnaire was developed by the researcher. It is a fivepoint Likert scale with minimum score ' 0 ' and maximum score ' 4 '. Scores were interpreted as 'most favorable attitude', 'favorable attitude' and 'unfavorable attitude'. The Cronbach ' $\alpha$ ' value of attitude tools was 0.86 .

\section{Sample size and sampling technique}

Simple random sampling technique was adopted by the investigator to select the samples. From $10^{\text {th }}$ to $12^{\text {th }}$ standards, the school had a total of 24 sections. In each of the sections the researcher selected 5 adolescent girls randomly and thus a total of 120 students were selected and the risk assessment questionnaire developed by Shoba., et al. [16] was administered. While analyzing the risk assessment questionnaire, it was is found that 'high risk', 'moderate risk', 'low risk' and 'no risk' students were 4, 36, 65 and 15 respectively. Among these 120 students, 'high risk' $(n=4)$ and 'moderate risk' ( $\mathrm{n}=36$ ) adolescent girls were segregated and thus making a total of 40 students. These 40 adolescent girls were again randomly divided in to experimental and control group and the intervention are given by the researcher. After that pre-test on knowledge and attitude assessment was done by the researcher. The next day awareness program was given by the researcher. By the end of the seven days post-test on knowledge attitude assessment was performed by the researcher.

\section{Intervention}

\section{Activity 1: Awareness program}

This session had 45 minutes Lecture with PowerPoint presentation given by the Researcher about, definition, causes, pathophysiology, complication, and prevention of PCOS. 
Activity 2: Yoga session

During this session, Yogasana was given by the researcher 30 minutes daily morning for 3 days. The Yogasanas included Pranayama, Bhadrasana, Chakki Chalanasana, Bharadvajasana and Sun salutation.

\section{Activity 3: Exercise session}

Three days brisk walking exercises given by the researchers for 30 minutes.

All the above three sessions were conducted in coordination with the schoolteachers at the school.

\section{Data analysis}

The filled knowledge and Attitude questionnaires were entered in to the SPSS and demographic variables, risk assessment, knowledge and attitude questionnaire were analyzed. The pretest and posttest knowledge score and attitude score were confirmed by' 'independent t test'.

Results

Demography assessments

Demographic characteristics of study subjects

In the experimental group $12(60 \%)$ of the girls age is 16 and 20 $(100 \%)$ of the girls attained age of menarche in 11 - 14 yrs. Further

\begin{tabular}{|c|c|c|c|c|c|}
\hline \multirow{2}{*}{ Parameters } & \multirow{2}{*}{ Variables } & \multicolumn{2}{|c|}{ Experimental group) $(n=20)$} & \multicolumn{2}{|c|}{ Control group $(n=20)$} \\
\hline & & $\mathbf{n}$ & $\%$ & $\mathbf{n}$ & $\%$ \\
\hline \multirow[t]{3}{*}{ Age } & 15 & 4 & 20 & 5 & 25.00 \\
\hline & 16 & 12 & 60 & 7 & 35.00 \\
\hline & 17 & 4 & 20 & 8 & 40.00 \\
\hline \multirow[t]{3}{*}{ Class } & 10 & 4 & 20.00 & 5 & 25.00 \\
\hline & 11 & 12 & 60.00 & 7 & 35.00 \\
\hline & 12 & 4 & 20.00 & 8 & 40.00 \\
\hline \multirow[t]{4}{*}{ Residence } & City & 5 & 25.00 & 5 & 25.00 \\
\hline & Rural & 7 & 35.00 & 3 & 15.00 \\
\hline & Sub Urban & 5 & 25.00 & 4 & 20.00 \\
\hline & Urban & 3 & 15.00 & 8 & 40.00 \\
\hline \multirow[t]{2}{*}{ Type of family } & Joint Family & 8 & 40.00 & 5 & 25.00 \\
\hline & Nuclear & 12 & 60.00 & 7 & 35.00 \\
\hline \multirow[t]{3}{*}{ Religion } & Hindu & 19 & 95.00 & 13 & 65.00 \\
\hline & Christian & 1 & 5.00 & 18 & 90.00 \\
\hline & Muslim & 0 & 0.00 & 1 & 5.00 \\
\hline \multirow[t]{4}{*}{ Number of siblings } & None & - & - & 1 & 5.00 \\
\hline & 1 & 9 & 45.00 & 1 & 5.00 \\
\hline & 2 & 4 & 20.00 & 10 & 50.00 \\
\hline & 3 & 7 & 35.00 & 7 & 35.00 \\
\hline \multirow[t]{3}{*}{ Order of child } & 1 & 11 & 55.00 & 2 & 10.00 \\
\hline & 2 & 5 & 25.00 & 12 & 60.00 \\
\hline & 3 & 4 & 20.00 & 6 & 30.00 \\
\hline \multirow[t]{2}{*}{ Age at menarche } & $11-14$ & 20 & 100 & 2 & 10.00 \\
\hline & $15-18$ & 0 & 0 & 18 & 90.00 \\
\hline
\end{tabular}

Table 1: Demographic characteristics of the respondents $(n=40)$.

details regarding the demographic details of the study subjects are tabulated in table 1 .

Demographic characteristics of parents

Majority of the fathers in experimental group was daily wages and none of the respondent family income is more than Rs. 7000 (USD = approximately 70.00 INR). Among control groups, most of the parents were daily wages and semiskilled $6(30 \%)$ and only 4 $(20 \%)$ of the respondents' family income is more than 7000 . Further details regarding the demographic details of the study subjects are tabulated in above table 2 .

Sources of information relied by the respondents: Table 3 Shows the frequency and percentage of the sources of information relied by the respondents in relation to health information. 


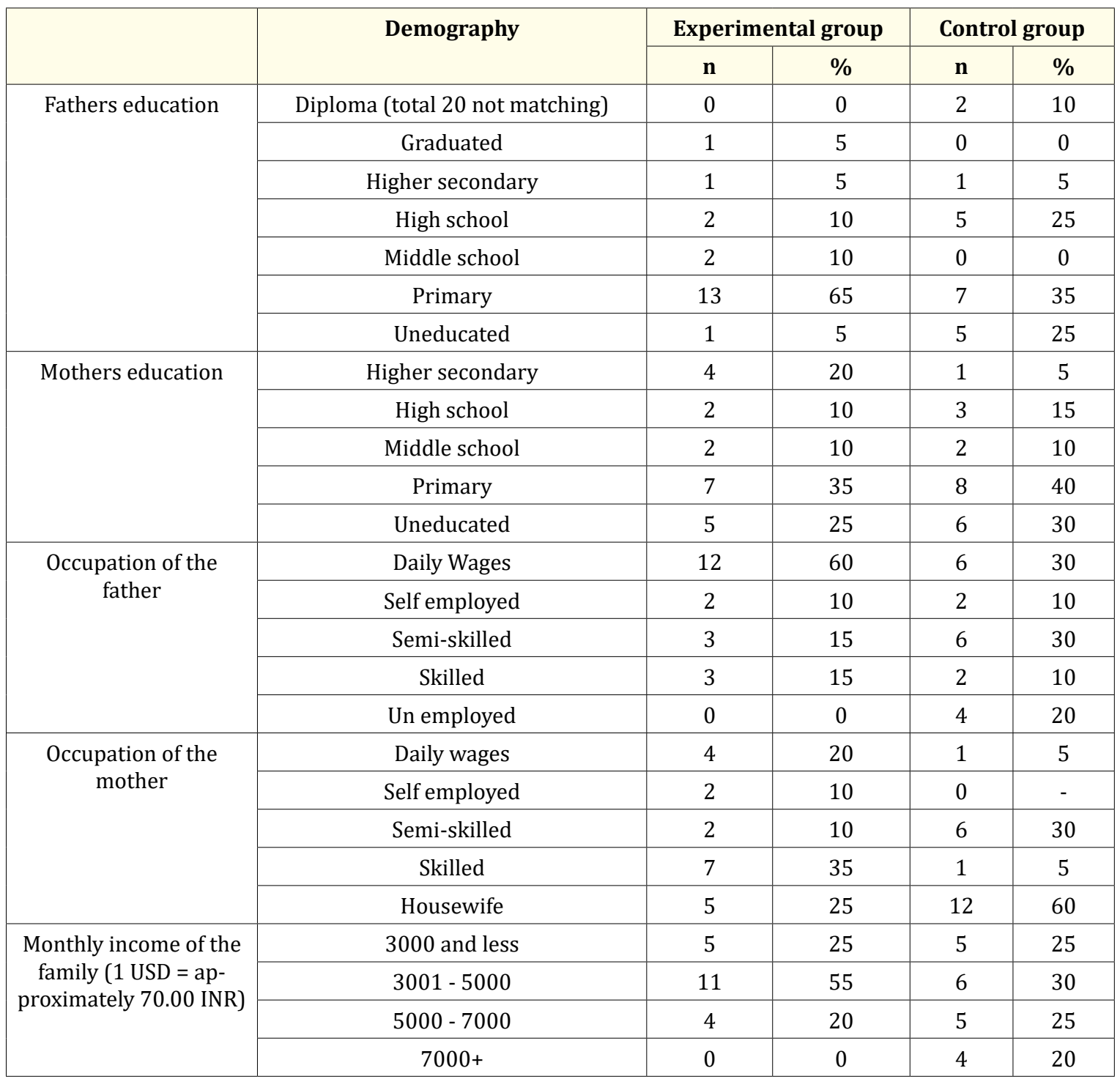

Table 2: Demographic characteristics of respondents' parents.

Note: The total numbers may not match as few of the respondents might have not filled certain responses.

\begin{tabular}{|l|c|c|c|c|}
\hline \multirow{2}{*}{$\begin{array}{c}\text { Sources of } \\
\text { information }\end{array}$} & \multicolumn{2}{|c|}{ Experimental group } & \multicolumn{2}{c|}{ Control group } \\
\cline { 2 - 5 } & $\mathbf{n}$ & $\mathbf{\%}$ & $\mathbf{n}$ & $\mathbf{\%}$ \\
\hline Books & 2 & 10.00 & 0 & 0 \\
\hline Friends & 2 & 10 & 3 & 15 \\
\hline Health personal & 3 & 15 & 0 & 0 \\
\hline News paper & 0 & 0 & 2 & 10 \\
\hline Television & 1 & 5 & 3 & 15 \\
\hline No information & 12 & 60 & 12 & 60 \\
\hline
\end{tabular}

Table 3: Frequency and percentage of the sources of information relied by the respondents.

\section{Risk assessment}

\section{Clinical profile of risk girls}

Table 4 shows that the comparison of the total scores of height, weight and body mass index was found to be 157.11, 47.30, 20.31

in experimental group and 153.30, 47.30, 0.11 in control group respectively.

Impact of intervention on risk scores: In the experimental group, most of the respondents 19 (95\%) were having moderate risk and only 1 (5\%) were having high risk. In control group all the respondents were having moderate risk and none of them were had high risk. In posttest experimental group 18 (90\%) were having moderate risk and only $2(10 \%)$ were having high risk (Table 5).

\section{Knowledge assessment}

Knowledge score evaluation

Table 6 shows the frequency and percentage of pretest level of knowledge in experimental and control group. In pretest experimental group majority of the respondents 16 (80\%) were having moderate knowledge. Remaining 3 (15\%) were having in adequate knowledge and only $1(5 \%)$ respondents having adequate knowl- 


\begin{tabular}{|l|c|c|c|c|}
\hline \multirow{2}{*}{$\begin{array}{c}\text { Clinical } \\
\text { profile }\end{array}$} & $\begin{array}{c}\text { Experimen- } \\
\text { tal group }\end{array}$ & $\begin{array}{c}\text { Control } \\
\text { group }\end{array}$ & t-value & p-value* \\
\cline { 2 - 5 } & Mean value & Mean value & & \\
\hline Height & 157.11 & 153.30 & 2.01 & 0.05 \\
\hline Weight & 50.15 & 47.30 & 0.88 & 0.39 \\
\hline $\begin{array}{l}\text { Body mass } \\
\text { index }\end{array}$ & 20.31 & 20.17 & 0.11 & 0.92 \\
\hline
\end{tabular}

Table 4: Comparison of the total scores of clinical profile of risk girls (experimental group and control group).

$P$ value of $<0.05$ was taken as statistically significant.

$$
*=\text { independent ' } s \text { ' test. }
$$

\begin{tabular}{|c|c|c|c|c|c|}
\hline \multicolumn{2}{|c|}{ Risk level } & \multicolumn{2}{c|}{$\begin{array}{c}\text { Experimental } \\
\text { group }\end{array}$} & \multicolumn{2}{c|}{ Control group } \\
\cline { 3 - 6 } \multicolumn{2}{|c|}{} & n & $\%$ & n & $\%$ \\
\hline \multirow{2}{*}{ Pretest } & Moderate risk & 19 & 95 & 20 & 100 \\
\cline { 2 - 6 } & High risk & 1 & 5 & 0 & 0 \\
\hline \multirow{2}{*}{ Post test } & Moderate risk & 18 & 90 & 18 & 90 \\
\cline { 2 - 6 } & High risk & 2 & 10 & 2 & 10 \\
\hline
\end{tabular}

Table 5: Pretest and posttest frequency and percentage of risk assessment.

\begin{tabular}{|l|c|c|c|c|c|}
\hline \multirow{4}{*}{$\begin{array}{c}\text { Knowledge } \\
\text { Level }\end{array}$} & \multicolumn{2}{|c|}{$\begin{array}{c}\text { Experimental } \\
\text { Group }\end{array}$} & \multicolumn{2}{c|}{ Control Group } \\
\cline { 3 - 6 } & & $\mathbf{n}$ & $\mathbf{\%}$ & $\mathbf{n}$ & $\mathbf{\%}$ \\
\hline \multirow{3}{*}{ Pre test } & In adequate & 3 & 15 & 3 & 15 \\
\cline { 2 - 6 } & Moderate & 16 & 80 & 15 & 75 \\
\cline { 2 - 6 } & Adequate & 1 & 5 & 2 & 10 \\
\hline Post test & In adequate & 1 & 5 & 2 & 10 \\
\cline { 2 - 6 } & Moderate & 4 & 20 & 9 & 45 \\
\cline { 2 - 6 } & Adequate & 15 & 75 & 9 & 45 \\
\hline
\end{tabular}

Table 6: Knowledge score evaluation.

edge. In control group majority of the respondents were 15 (75\%) having moderate knowledge.

Impact assessment of intervention on knowledge scores

Table 7 shows the impact assessment of intervention on knowledge scores among both the groups.

Attitude assessment

Table 8 shows the difference in the pretest and posttest attitude in experimental group confirmed by the independent ' $t$ ' test (2.83), which was significant at $\mathrm{p}<0.001$. The difference in the pretest and post test scores of the attitude in control group confirmed by the independent ' $t$ ' test (2.99), which was significant at $\mathrm{p}<0.001$.

\begin{tabular}{|l|c|c|c|c|c|c|}
\hline \multicolumn{1}{|c|}{ Group } & Knowledge & $\mathbf{n}$ & Mean & SD & t-value & p-value \\
\hline \multirow{2}{*}{ Experimental } & Pretest & 20 & 11.30 & 2.25 & \multirow{2}{*}{5.27} & 0.000 \\
\cline { 2 - 7 } & Post test & 20 & 16.85 & 4.91 & & \\
\hline \multirow{2}{*}{ Control } & Pretest & 20 & 11.25 & 3.51 & 2.85 & 0.01 \\
\cline { 2 - 6 } & Post test & 20 & 14.35 & 4.44 & & \\
\hline
\end{tabular}

Table 7: Impact assessment of intervention on knowledge scores. $P$ value of $<0.05$ was taken as statistically significant.

$$
*=\text { Independent ' } \mathrm{t} \text { ' test. }
$$

\begin{tabular}{|l|c|c|c|c|c|c|}
\hline \multicolumn{1}{|c|}{ Group } & Attitude & $\mathbf{n}$ & Mean & SD & t-value & p-value \\
\hline \multirow{2}{*}{ Experimental } & Pretest & 20 & 51.80 & 11.12 & 2.83 & 0.01 \\
\cline { 2 - 5 } & Post test & 20 & 59.85 & 6.41 & & \\
\hline \multirow{2}{*}{ Control } & Pretest & 20 & 53.05 & 5.92 & 2.99 & 0.01 \\
\cline { 2 - 5 } & Post test & 20 & 53.45 & 5.91 & & \\
\hline
\end{tabular}

Table 8: Attitude assessments.

$P$ value of $<0.05$ was taken as statistically significant.

$$
*=\text { Independent ' } \mathrm{t} \text { ' test. }
$$

\section{Discussion}

Uncontrolled PCOS is associated with pregnancy-induced hypertension, preeclampsia, gestational diabetes mellitus, hypertension, dyslipidemia, type-2 diabetes mellitus, mood disorders, and can lead to increased cancer risks [17]. This research identified beneficial effects of lifestyle modifications on PCOS risk among adolescent girls and in addition showed positive impact on their knowledge and attitude towards PCOS. It is well known that exercise helps to improves autonomic function and inflammatory pattern in women with PCOS. In this study, the experimental group students had a better improvement in their PCOS risk reduction. Since their knowledge and attitude also increased, this positive outcome may provide a sustainable reduction in further PCOS risk.

Health education is crucial since it largely influence the manner which it is responded. Often mothers are the source of health education on early symptoms identification and eating habits of their daughters. A similar study conducted at Egypt [18] showed that that only a few mothers were graduates. A mother's response to health problem of the child is deemed crucial $[19,20]$. Family income may be considered as a predictor for PCOS risk as it is linked with eating junk foods. However, in studies from India [16] and Saudi, the level of monthly income did not have any influence PCOS knowledge [21].

In the present study most of the participants did not had any information on PCOS and their dependence on resources such as newspapers, television, etc were minimal. However, few of them had received minimum info only from friends, health personnel and books. These findings were associated with a study in which $80(100) \%$ had no information about PCOS [22]. Another study 
showed that $19 \%$ had information from their friends, $3.5 \%$ from newspaper and $28 \%$ were unaware about PCOS [23]. The intervention in the current research is targeted at motivating students to learn more about PCOS through all available resources.

Most of the respondents had moderate risk and only very few had high risk. In one study, authors found menstrual cycle disorder, bad mood, family history of diabetes, and family history of infertility menstrual irregularity of mother and lack of physical exercise as risk factors for PCOS [24]. This research did not focus much on PCOS risk reduction as it was conducted only for a short period. Long term studies will be valuable in identifying impact of such interventions on PCOS risk reduction.

During pre-test phase of the current research, majority of the girls had inadequate knowledge, which upon intervention turned much better post intervention. A study from Egypt assessed the impact of an educational program on PCOS among adolescent girls and researchers found enhancement of knowledge scores which was poor in case of $84 \%$ of the students prior to the intervention [15]. It is important to have a sustainable improvement in knowledge scores as it can potentially improve the attitude and practice towards PCOS. In this research efforts have been put to improve various aspects of knowledge such as pathophysiology, symptoms, causes of PCOS etc.

During pre-test majority of them had unfavourable attitude towards PCOS. After intervention, majority of them had favourable attitude. One study from The Netherlands evaluated the relationship between PCOS characteristics and psychological wellbeing. The results revealed notable impairment of psychological wellbeing of the individuals with PCOS symptoms [25]. Hence it is important for any interventions should focus on improving the psychological features of the individuals with PCOS. There is a possibility that the respondents between the control and experimental groups interacted and discussed on the topics related to PCOS and thus making it a potential limitation of this research.

\section{Conclusion}

The findings of this research show the improvement in knowledge and attitude scores upon educational intervention. Thus, it is feasible to incorporate an education module for school going adolescent girls at risk for PCOS and helping in early identification and prevention of the illness.

\section{Acknowledgements}

Authors acknowledge all the students who actively participated in this research. Special thanks to the schoolteachers and School administration for their participation and granting permission.

\section{Source of Funding}

Nil.

\section{Conflict of Interest}

None.

\section{Bibliography}

1. Azziz Ricardo., et al. "The prevalence and features of the polycystic ovary syndrome in an unselected population". The Journal of Clinical Endocrinology and Metabolism 89.6 (2004): 2745-2749.

2. Gordon Catherine M. "Menstrual disorders in adolescents: excess androgens and the polycystic ovary syndrome". Pediatric Clinics of North America 46.3 (1999): 519-543.

3. Clark Nina M., et al. "Prevalence of polycystic ovary syndrome phenotypes using updated criteria for polycystic ovarian morphology: an assessment of over 100 consecutive women selfreporting features of polycystic ovary syndrome". Reproductive Sciences 21.8 (2014): 1034-1043.

4. Sheelaa W and Rekha Radha. "The prevalence and features of the polycystic ovary syndrome in young South Indian women from Pondicherry". International Journal of Reproduction, Contraception, Obstetrics and Gynecology 3 (2014): 344.

5. Hardy Tristan SE and Robert J Norman. "Diagnosis of adolescent polycystic ovary syndrome". Steroids 78.8 (2013): 751754.

6. March Wendy A., et al. "The prevalence of polycystic ovary syndrome in a community sample assessed under contrasting diagnostic criteria". Human Reproduction 25.2 (2010): 544-551.

7. Jonard Sophie., et al. "Ultrasound examination of polycystic ovaries: is it worth counting the follicles?". Human Reproduction 18.3 (2003): 598-603.

8. Nidhi Ram., et al. "Effect of holistic yoga program on anxiety symptoms in adolescent girls with polycystic ovarian syndrome: A randomized control trial". International Journal of Yoga 5.2 (2012): 112.

9. Tang Thomas., et al. "Combined lifestyle modification and metformin in obese patients with polycystic ovary syndrome. A randomized, placebo-controlled, double-blind multicentre study". Human Reproduction 21.1 (2006): 80-89.

10. Clark AM., et al. "Weight loss in obese infertile women results in improvement in reproductive outcome for all forms of fertility treatment". Human Reproduction 13.6 (1998): 1502-1505.

11. Teede Helena., et al. "Polycystic ovary syndrome: a complex condition with psychological, reproductive and metabolic manifestations that impacts on health across the lifespan". BMC Medicine 8.1 (2010): 41. 
12. Barber TM., et al. "Obesity and polycystic ovary syndrome". Clinical Endocrinology 65.2 (2006): 137-145.

13. Legro Richard S. "Polycystic ovary syndrome and cardiovascular disease: a premature association?". Endocrine Reviews 24.3 (2003): 302-312.

14. Smith Caroline., et al. "A randomised comparative trial of yoga and relaxation to reduce stress and anxiety". Complementary Therapies in Medicine 15.2 (2007): 77-83.

15. Shanti S and K Perumal. "Kayakalpa Yoga, A Treasure Hunt for Women with PCOS and Infertility: A Pilot Trial". Research and Reviews: A Journal of Unani, Siddha and Homeopathy 1.3 (2014): 12-23.

16. Devi Elsa Sanatombi and Anusuya Prabhu. "An exploratory survey to identify the adolescents with high risk for Polycystic Ovarian Syndrome (PCOS) and to find the effectiveness of an awareness programme among students of selected pre-university colleges of Udupi District". IOSR Journal of Nursing and Health Science 3.3 (2014): 66-69.

17. Palomba Stefano., et al. "Complications and challenges associated with polycystic ovary syndrome: current perspectives". International Journal of Women's Health 7 (2015): 745.

18. Mohamed Hoda Abdel Azim. "Effect of educational program on the level of knowledge regarding polycystic ovarian syndrome among adolescent girls". Journal of Nursing Education and Practice 6.10 (2016): 80-87.

19. Al-Ayed and Ibrahim H. "Mothers' knowledge of child health matters: Are we doing enough?". Journal of Family and Community Medicine 17.1 (2010): 22.

20. Frost Michelle Bellessa., et al. "Maternal education and child nutritional status in Bolivia: finding the links". Social Science and Medicine 60.2 (2005): 395-407.

21. Alessa Amal., et al. "Awareness of polycystic ovarian syndrome among Saudi females". International Journal of Medical Science and Public Health 6.6 (2017): 1013-1020.

22. Upadhye Jayshree J and Chaitanya A Shembekar. "Awareness of PCOS (polycystic ovarian syndrome) in adolescent and young girls". International Journal of Reproduction, Contraception, Obstetrics and Gynecology 6.6 (2017): 2297-301.

23. Sowmya MA and Philomena Fernandes. "Effectiveness of structured teaching programme on knowledge of Polycystic Ovarian Syndrome among adolescent girls". Nitte University Journal of Health Science 3.3 (2013): 54.
24. Shan Bao., et al. "Risk factors of polycystic ovarian syndrome among Li People". Asian Pacific Journal of Tropical Medicine 8.7 (2015): 590-593.

25. De Niet JE., et al. "Psychological well-being and sexarche in women with polycystic ovary syndrome". Human Reproduction 25.6 (2010): 1497-1503.

\section{Assets from publication with us}

- Prompt Acknowledgement after receiving the article

- Thorough Double blinded peer review

- Rapid Publication

- Issue of Publication Certificate

- High visibility of your Published work Website: www.actascientific.com/ Submit Article: www.actascientific.com/submission.php Email us: editor@actascientific.com Contact us: +919182824667 